Ageing and Society 21, 2001, 777-798. (C) 200 I Cambridge University Press

DOI: го.гі7/Sor44686Xor 008492 Printed in the United Kingdom

\title{
'You're never too old': beliefs about physical activity and playing sport in later life
}

\author{
BEVAN C. GRANT*
}

\begin{abstract}
It was evident from interviews with 5 men and women over 70 years of age that the experiences derived from being physically active and playing sport in later life are expansive, dynamic and completely imbued with multiple interpretations. Furthermore, their beliefs support the notion that the physically active body should be considered more than a physical object, as it represents a conscious, feeling, thinking and reflective self. The findings signify much is to be gained by regularly partaking in deliberate physical activity during later life although this is not always as easy as it sounds. At a personal level, changes in functional capacity and dealing with the sometimes ailing body can serve as a deterrent. From a broader perspective, the stigma associated with being older also poses a significant physical, sociological and psychological challenge, particularly during the initial phases. In conclusion, the study discusses why change must occur at a personal and societal level before a greater proportion of the older population become more physically active.
\end{abstract}

KEY WORDS - physical activity, sport, health, beliefs, barriers.

\section{Introduction}

As men and women are now living longer and deemed to be in better health than previous generations, it is not surprising that increasing numbers of older people are choosing to participate in a more diverse range of leisure activities. What is more, the stereotypical views and images associated with ageing are gradually being challenged (Greenwald I997). Rather than being 'over the hill', more and more older people are 'taking the hill by storm' and seeking opportunities to be involved in a multitude of activities, some new and others rekindled from earlier years. Although ageing may impose some constraints and be defined in numerous ways, most older people tend to describe their

* Department of Sport and Leisure Studies, University of Waikato, New Zealand. 
state of health and wellbeing in positive terms (Atchley r 999; Hepworth I995; Roberts i999). However, there is concern amongst health professionals regarding the high proportion of those in later life who, in many cases unintentionally, allow physical activity to become more of a memory than a regular occurrence (Blair and Wei 2000; Dishman 200 г; O'Brien Cousins 200 г; Rowe and Kahn i998; World Health Organisation 1997). One response to this has been a proliferation of community-based exercise programmes designed specifically to accommodate the needs and interests of this section of the population. In addition, there has been a proliferation of research in this area of gerontology, focusing primarily on the physical body and symptoms of decline. As for other areas of research on ageing, there is a tendency to ignore older people's perceptions and beliefs about the way ageing is experienced (Carlsen I996; Heikkinen 2000; Hepworth 2000; Jamieson et al. 1997) and, in particular, the role and meaning of physical activity in later life (Grant and O'Brien Cousins 200I).

This article has three purposes; first, to reflect on how ageing and physical activity has been articulated in the literature; secondly, to examine the beliefs of a group of men and women over 70 years about the role and meaning of physical activity, including playing sport, in later life; finally, to draw on these beliefs and to consider some of the issues older people encounter in negotiating socio-cultural expectations and personal events when endeavouring to incorporate regular physical activity as an inherent part of their lifestyle.

\section{Ageing and physical activity}

Irrespective of age, there is overwhelming evidence to support the benefits of maintaining a physically active lifestyle and how such behaviour can contribute to quality of life and the 'feel better phenomenon' (e.g. Mathieu i 999; Ruchlin and Lachs i 999; Spirduso I 995). Furthermore, our understanding about the causal relationship between ageing and physical activity on factors such as functional capacity, motor ability, psychological health, cognitive functioning and well-being is well advanced (Chodzko-Zajko 2000; Huber i 997; Kilgman et al. ı999; O'Brien Cousins and Horne r999; Shepherd I 997; Spirduso I 995). Although increasing numbers of older people are participating in programmes specifically designed for older people $(e . g$. aqua jogging for seniors, 6o-plus walking groups, Masters Games), several national surveys (e.g. in Canada, Australia, New Zealand, United Kingdom and the USA) indicate only a minority regularly 
engage in a level of physically active leisure considered sufficient to deter the onset of functional incapacity (Dunlap and Barry r 999; Huber I997; Mathieu ı999; Satariano et al. 2000; Wolinsky et al. I 995). This endorses the argument of Kelly ( I 993: I 23) that no type of leisure activity is more likely to be abandoned or avoided by the old as regular physical exercise especially if it requires considerable exertion. In spite of a trend to withdraw from being physically active, the majority of older people agree that physical exercise is ' good for you' (O'Brien Cousins and Janzen I998) but fail to adhere to such behaviour (Dishman 200I). Although no common explanation exists for the contradiction between belief and action, Roberts ( I999: I39) postulates that the poverty of their childhood socialisation into organised physical activity (including sport), and the limited opportunities available after leaving school, have a lasting effect that is difficult to change as one ages. The barriers may be both real and perceived, situated in self and others, and may reflect the culture in which we live. Furthermore, many people in later life, especially women, feel physically and socially vulnerable when participating in mild to moderately intense physical activity. They are worried about 'wearing out' and incurring sudden injury (O'Brien Cousins 2000; Vertinsky I 995). Changing behaviour is a complex phenomenon and, as Slater (I995: 4I) suggests, it is unlikely that the future will see masses of people in later life take up leisure-time activities to which they are unaccustomed or with which feel insecure.

A further explanation for the dominant pattern of sedentary behaviour amongst older people relates to their perception about their personal state of health, and includes beliefs about what the older body should and should not do. This is inextricably linked to a gradual accumulation of not only the inevitable biological processes but also attitudes, expectations, prejudices, cultural values and ideals of the society in which individuals develop and grow old (Blaikie i999; Featherstone and Hepworth i 995; Heikkinen 2000; Hepworth I995; Poole and Feldman I999; Roberts I999). This being the case, it is surprising that only a few studies report the views of older people in regard to these matters. For example, through interviews with women who are over 50 and participating in fitness classes, Poole (200I) discovered that the women's exercise experiences were often contradictory. There tended to be an emphasis in fitness classes on the improved body, something which seemed to be partially influenced and regulated by a complex of messages about the ideal body size and shape exuding from a variety of images including those promoted by the beauty and health industries. On the other hand, the women did 
not attend exercise classes merely for a better-looking body, but also to gain strength and mobility for independent living; to create social networks with other women; to have time for themselves; and to be with others of a similar age. These are all reasons that Poole identified as empowering older women. Whilst this may be the case for some, Vertinsky ( I 995) reported that many older women hold strong beliefs about the assumed risks that deterred them from participating in anything more than gentle exercise. She also discussed how health is misunderstood when considered solely in biological terms, as it represents the power of cultural images and stereotypes concerning ageing and physical activity. This was reflected in a study by $\mathrm{O}$ 'Brien Cousins (2000) who reported that the beliefs older women had about being too active far exceeded the known potential benefits. For example, many of the participants expressed the view that their hearts 'couldn't take it'. These studies clearly identify how perceptions rather than reality can influence whether or not one will engage in deliberate physical exercise. They also reflect a claim by Featherstone and Hepworth (I995: 3I) that socially constructed beliefs and values are very influential on the way one behaves in a specific culture. Although older adults now live in a new cultural period where old muscles are suppose to be moved, O'Brien Cousins (2000) noted that until recently older people were cautioned against undertaking such action. After all, rest was once considered the virtue of old age (Kirk I997).

\section{Beyond the physical}

To better understand the views of active and inactive older persons, there is a call to look beyond the physical 'self' and consider the 'other self' (Grant and Stothart i 999; Henderson et al. i 999; Kluge 200 I; McPherson i 994; Markula et al. 200 I; Vertinsky i 995). According to Kenyon and Randall ( I 997: I I) there is a need to get inside ageing as it is experienced and expressed by older people. Too often in the study of ageing we lose sight of the lived body (Featherstone and Wernick I 995: I ). Ageing cannot be understood solely as a biological process; hence the need to establish a new discourse that more fully explores and explains the meaning of later life (Featherstone and Hepworth i 995). This 'losing sight' is best illustrated in the Fournal of Ageing and Physical Activity where, since its inception in I 993, approximately 95 per cent of

the published research, positions the person as an object of investigation, something to be treated and/or measured and reported on, 
in a way that assumes that generalisations can be extrapolated to this sector of the population. Nevertheless, this research has made a notable contribution to our understanding about many aspects of physical activity in the later years (Grant and O'Brien Cousin 200I) but, as stated by Kuhn (I970), no one paradigm can capture all the subtle variations of any phenomenon.

The study of active ageing consists not only of reports about so-called facts and scientific explanations about physiological and psychological processes, but also descriptions of the meaning people attribute to their experiences of physical activity. To date, studies seeking alternative bodies of knowledge remain seriously under-represented in the field of gerontology (Abel and Sankar i 995:3); the dominant story of ageing tends to follow the reductionist model commonly associated with medicine and psychology (Blaikie r 999). Consequently, there is a great deal written about such things as physical performance, functional capabilities, and psychological state, but those aspects considered ineffable and non-quantifiable have been omitted. Some years ago Willing ( 198 I : 38 ) warned of such an outcome when suggesting that, by relying on quantitative research, the stories of ageing may be accurate without being true, may represent the experience yet omit the essence of it: the humanity of the person whose experience it was. Following an extensive review of the literature on ageing and physical activity O'Brien Cousins and Horne (I999) concluded that our knowledge is both advanced and limited by the positivist discourse. Hence, the story is far from complete. With few exceptions the central character (i.e. the older person) is hidden from the research text on ageing and physical activity. However, in those few studies where the older person is given a voice (e.g. Hardcastle and Taylor 200 I ; Kluge 200 I ; Langley and Knight I999; O'Brien Cousins 2000; Poole 200 I ; Vertinsky I995), it is evident that a continual refining and redefining of the physical, social, psychological and cultural self occurs across the life course. These studies echo the views of Sankar and Gubrium (I 994) who argued that greater emphasis should be attributed to the meanings older people ascribe to their experiences, as they know their lives, one another and their respective worlds.

When commenting about research on changing patterns of exercise behaviour, Tinning ( I997: i I 6) called for a move beyond the dominant scientific and performance discourse. He claimed that relying on information derived from this paradigm is of little help with enticing a greater proportion of the population to increase their level of physical activity. Makosky ( I996) presented a similar view, claiming our understanding of physical inactivity could possibly change by adopting 
a more humanistic and subjective perspective rather than relying solely on a normative, mechanical and scientific view. Given that physical activity means different things to different people, and many of the benefits are subjective, intangible and impossible to quantify, adopting an alternative theoretical position would be desirable. Accepting such a notion would require incorporating a range of visions and voices into the research agenda in order to capture a more informed meaning about this aspect of an older person's life. Supporting such a position, Kerry and Armour (2000) discussed how meaning and movement are inextricably bound and, in order to advance the field of inquiry about ageing and active living, we should move beyond the objective body. This means finding out more about the meaning-making self (Carlsen I 996) and acknowledging that our bodies are not just experienced as physical objects. Irrespective of our age, we are all conscious, feeling, thinking and reflective, and impute meanings to what is happening in our lives. Hence, the meanings attributed to the physical activity experiences can and should be 'captured' to explicate the diversity we know exists.

\section{Method}

This research is located within the interpretive paradigm (Sparkes I 992) and based on open-ended in-depth interviews with eight women and seven men over 70 years of age who recently participated in the South Pacific Masters Games. Approval to conduct the study was granted by the author's University Ethics Committee and access to the participants provided by the organising committee of the Games. All participants (referred to in the paper by pseudonyms) gave informed written consent. As shown in Table $\mathrm{I}$, the participants ranged in age from $7 \mathrm{I}$ to 79 years, several had lost their spouse and all reported having endured some form of physical inhibition and/or psychological distress during their later adulthood. Nevertheless, all described their current state of health as 'very good'. For most, their chosen sports had not been played competitively before 6o years of age. Over all, they were a very heterogeneous group and had varied backgrounds in education, socio-economic status, leisure-time interests and sporting experience.

During the interviews each participant meandered across many life events. According to Ruth and Kenyon ( I 996) this is common, as older people tend to talk about themselves by reflecting back on their past in

order to make a coherent and credible account of current experiences 
T A в L e I. Sample by pseudonym, age, marriage status, health ailment, competitive sport $(s)$

\begin{tabular}{|c|c|c|c|c|}
\hline Pseudonym & Age & Marriage status & Health ailment & Competitive sport \\
\hline Diane & 74 & widowed & asthma $^{1}$ & tennis, swimming ${ }^{2}$ \\
\hline Berl & 76 & married & arthritis & croquet $^{2}$ \\
\hline Edith & $7 \mathrm{I}$ & widowed & breast cancer & badminton $^{2}$ \\
\hline Jill & 75 & married & reduced eye sight & bowls \\
\hline Joan & 78 & married & mild depression $^{1}$ & athletics \\
\hline Sue & $7 \mathrm{I}$ & widowed & hip replacement & swimming \\
\hline Mary & 74 & widowed & cardiac condition & bowls, golf ${ }^{2}$ \\
\hline Ruth & 73 & single & arthritis & line dancing ${ }^{2}$ \\
\hline Tim & $7 \mathrm{I}$ & married & hip replacement & cycling, swimming \\
\hline Richard & 73 & widowed & heart attack & swimming, golf ${ }^{2}$ \\
\hline Ross & 74 & married & mild depression & tennis, badminton ${ }^{2}$ \\
\hline Bill & 77 & widowed & arthritis & bowls $^{2}$ \\
\hline Les & 75 & married & diabetic $^{1}$ & tennis, golf ${ }^{2}$ \\
\hline Ted & 72 & married & cardiac condition & athletics \\
\hline David & 74 & married & emotional disorder ${ }^{1}$ & golf $^{2}$, running \\
\hline
\end{tabular}

1 Condition first occurred since turning 60 years of age.

2 First participated in competition in this sport since turning 60 years of age.

and feelings. Throughout each interview primacy was given to asking 'what' rather than 'why' about the beliefs participants had about the role of physical activity in the later years, about their own life and in particular about their recent sporting experiences. Each participant was interviewed at least twice for 45 to 80 minutes at a time. At the conclusion of the interviews all participants were brought together for a focus group, during which they were asked to reflect on and clarify a number of common matters raised individually. All interviews and the focus group were audio-taped and transcribed verbatim.

The data were analysed using a process of inductive analysis and constant comparison. There was a conscious effort to avoid being too rule-bound and thereby constraining access to the multitude of meanings that exist in such data (van Manen i998). During the analytical process, a number of conceptual categories emerged, leading to the following three themes which provide a structure for the text: (i) mixed messages about ageing and physical activity, (ii) getting into sport, and (iii) serious play. The message within each theme is not intended to provide a definitive explanation of what is being studied. Rather, as Denzin (I997: I2) has stated, the researcher can only produce a text that reproduces a version of the real. Nevertheless, stories derived from this type of research respect and represent the voice of the participants, connect to the broader social and theoretical issues and, according to Denison and Rinehart (2000), have value and power in their own right to illuminate. 


\section{Mixed messages about ageing and physical activity}

Engaging in deliberate physical activity on a regular basis was described by all participants as doing something meaningful that provided a sense of satisfaction and, to quote Sue, a feeling of 'being in charge of your body'. This occurred in a different way for each individual. For example, Janet was an avid gardener and swam several times a week, Berl walked with a couple of friends most mornings and played indoor bowls twice a week, while Bill was a regular golfer and went to an aerobics class once a week. In spite of their current levels of activity, none of the participants had engaged in physical activity on a regular basis throughout their adult life. There had been times when work commitments, family responsibilities (e.g. raising their own children, caring for ill parents), health-related problems (see Table I) and social factors influenced their interest in and opportunity for involvement. They could all recall stories about the way their parents lived and how the inherent message seemed to be communicated: 'this is a time for disengagement':

Being physically active hasn't always been of great importance to me. I learned exercising wasn't something older people did. Although both my parents had physical type jobs they certainly weren't very active when they retired. Retirement equated to rest. (Richard)

My mother would have kept fit just by doing the chores around the home and my dad must have walked miles every day. I sometimes think they might have been fitter than I am. But I've outlived both their age. (Janet)

I learned [intuitively] from my parents that you rested when you were older. You certainly didn't spend time playing sport like I do, particularly if you were a woman ... but times are changing thank goodness. I can understand why many older women don't play sport. (Diane)

Whilst the participants acknowledged increasing numbers of people in the 65-plus age group are becoming more physically active, the common belief was that most older people avoided being more physically active than is necessary. Given the participants' own commitment to being physically active on a regular basis, it was not surprising they were mystified as to why 'being older' should be considered an excuse or motivation to be inactive. These sentiments were captured by Joan when suggesting:

Most older people have a sedentary lifestyle and are very unfit. I know some walk and I see a few at the pool and the gym but not many. ... I don't think age is the problem. It's the attitude about being physically active when you're older. Many people worry that they'll look silly or think it will be too hard. Quite a few older people that I know believe they shouldn't be too active. 
They say it's too late to start. Another thing that intrigues me is how they [inactive people] think they can remain healthy when they don't do anything [physical activity] at all.

There was a general perception that this attitude was the norm and gave ageing a 'bad name' (Ross). It also reinforced a commonly-held view that 'if we don't use it, we lose it' (Sue), a phrase believed by most to have an element of truth. Although none considered themselves to be old, most indicated they were still classified this way and frequently had to deal with associated negative connotations and expectations. Many endorsed the views of Bill who 'hated people saying that at your age you shouldn't be doing this or that. I don't understand why because I feel fine. It can be off-putting'. Edith reflected this in another way when stating 'many older people believe what they hear or read and, as a result, chose not to get out and be too active, they become afraid'. Although difficult to modify one's way of life, most believed:

The less you do the less you want to do. Being physically active on a regular basis can become a habit, a bit like watching television. But there's got to be a purpose and a feeling of satisfaction, otherwise why bother? (Ted)

What us oldies are doing is recycling, keeping busy, and not thinking about slowing down. Once you believe you should give up being physically active then it's downhill until the end, and that will come too soon. (Tim)

All participants acknowledged that during the past 20 years, significant changes had occurred in their physical competence and body function. It was evident that these changes in the physical body caused frustrations and that regular physical activity was deemed an important way to help negate the impact of these ailments. Most, however, indicated the struggle was not always easy to deal with as David noted:

My mind and body are often talking a different language, particularly when I'm at the gym. I don't particularly enjoy this situation and it's certainly not like it used to be a few years ago. Sometimes it's a struggle and sometimes it's not. But as far as I'm concerned I keep participating because I believe it's better than the other option, being inactive. To be honest, I don't really want to know what the other option is like.

Being born before I930, all participants had witnessed a range of opinions about what a 'healthy' lifestyle supposedly included. It is not surprising therefore, that many older people are confused about what one should or should not do in order to maintain a healthy existence. Even today, it is not the shortage of advice that is the problem, but rather the difficulty of discriminating what is appropriate and what is not from the plethora of messages offered via magazines, television, brochures and health professionals. A further concern is that much of 
the advice is prescriptive and implies a homogeneity: 'Do this and you improve your health, do that and something else happens. Sounds easy but in reality life's not like that' (David). Most participants believed that for some unknown reason, many older people had learned physical activity 'wasn't for older people' (Berl). They agreed that age was used too frequently solely as an excuse for avoiding being physically active: 'I think many 65-year-olds just think it's too late and convince themselves there's no point at this time in life, so why bother?' (Ross). However, the participants had very positive things to say about the benefits they experienced from being physically active, and how this was essential for maintaining their good state of health and well-being:

I'm absolutely certain that being active has helped keep my ailment under control for the past few years. Before my operation I felt quite depressed, but this has gone and I now feel as if there is a purpose for living. I'm doing something that really excites me and helps keep me relaxed. I've got a new lease of life. (Tim)

Even if you have some type of health problem I don't think it's too late to try and take care of yourself by partaking in some form of regular exercise. It doesn't need to be too strenuous. You learn so much about yourself, not just how well you can do the activity. After a good session I can be on an emotional high, a type of euphoria that takes my mind away from any discomfort with my arthritis. I'm sure being with others who are keen on the same thing as me makes a difference. We're a pretty social group and have a lot of fun. (Ruth)

As far as I'm concerned, after the problems I've had, I view the future as uncharted territory. I'm convinced that being active even in times of distress is one of the reasons why I'm still alive today. Sport gives me an interest away from the hard times in my life. I should have started playing sport much earlier in life. (Edith)

Most participants expressed concern about the way older people 'didn't take advantage of the many opportunities that are now available' (Tim) and 'stayed away from the programmes and community leisure facilities in droves' (Mary). Although there's no simple explanation, several of the participants thought a more inclusive and softer approach could be used in the messages intended to attract older people to join in. For example, Ruth thought 'promotional activities that use ordinary older people rather than skinny young bodies would be a good place to start. Don't they understand who we are and what we like?' In spite of some of the not-so-effective strategies currently being used, it was noted that several recent initiatives seemed more appealing but 'who knows if they are successful' (Richard). These included offering special rates for older people and ensuring that the images better reflected the older age group. Similarly Edith noted that 'involving the older people in the selection of activities has proved 
popular in several recreation centres'. In spite of additional community resources being spent on enticing older people to sign up with a programme, 'not everybody needs to belong to a group, you can exercise by yourself in lots of ways. I'm an avid jogger and like plodding around my favourite tracks by myself' (David). In spite of their enthusiasm for being physically active, all participants were aware this is only one way to seek self-fulfillment, maintain one's health and enjoy life in later years. They also agreed with Diana who noted the importance of having a range of interests that were personally fulfilling.

I'm a keen swimmer and love training and coaching, whereas my husband is not at all interested in this. In fact I sometimes think he is quite bored by it all. Much of my time is based around what's happening at the pool, usually getting ready for an event or helping out with the young age groups.... My husband is very involved in a choir, sings in concerts and at church, something in which I have little interest but go and listen ... they're not bad. In between times we both share a love for the garden.

\section{Getting into sport}

All participants played sport during their younger years but most stopped participating in organised competition within a few years of leaving school. For some this was not a complete withdrawal as they remained involved in different ways during part of their adult life. As Joan noted:

For many years I was a one of several parents that helped organise the local community athletic meeting. Although tempted from time to time I never had time to join in as the family duties and our business kept me far too busy. Plus I would have been the only one of my age so it would have been pointless.

When in their mid-5os or early 6os, all participants began to play sport again, either informally or in organised competition. Although not able to make a causal connection, this coincided with the "health and fitness movement' of the I 970 os when many multi-purpose community facilities were built and a variety of easily accessible activities (e.g. fun runs, mass aerobics, learn to swim campaigns, 'have-a-go' festivals, walking programmes) were provided by the public and private sector: 'There was a real push for people of all ages to participate which made joining in so much easier' (Ruth). In addition to the initiatives offered by organisations, there were also personal reasons why each person resumed playing sport:

I was talking to some younger friends about doing something different, maybe something physical which was a bit out of character for me given my lifestyle for the last 30 years. I hadn't done anything beyond my daily chores for years. 
There was a suggestion that I join my friends for a game of croquet, I didn't know the first thing about it but I must have liked it because 2 I years later I'm still playing. I know it looks slow but it's as much a mental game as a physical one and age is no barrier. (Berl)

I hadn't played sport for years and after spending a long time caring for my terminally ill husband, my neighbour said 'why don't you come and join us for a game of badminton? We're all beginners.' I was 59 then and have a vivid memory of that day. We had a lot of fun, no one was watching and I was amazed that it wasn't too hard. I haven't improved much but I'm still playing today with a group of women of similar age. (Edith)

Fourteen years ago I was in agony and finished up having an operation on my gall bladder. While looking out the hospital window I saw a group of middleaged guys jogging during their lunch hour. I'm not sure what happened but decided once I recovered I was going to get back into shape. A few months later and no more cigarettes, I was off to the gym and into a gentle walk-jog programme. My health really was a mess when I think about it. That's how it all began and it's never stopped. (Tim)

I was given a set of bowls for my 6oth birthday by an 'old' friend who was keen to get me involved. I would have never started by myself. Even though I had to have an unexpected operation soon after being given the bowls which forced me to stop playing for a couple of months. Apart from this interruption I've been playing ever since. (Jill)

One day after dropping my daughter off for her five kilometre training run home, I decided that I was going to join her. I used to run and had fond memories of those days. Not only were my family surprised when I announced my intentions but this was the start of what has been a memorable i 9 years of participating in athletics. (Joan)

None of the participants indicated it was easy to take-up playing sport after spending several decades of being a spectator and/or parent helper. Not only were few older people involved but ' the body didn't respond particularly well at first' (Ted). There was also a feeling that 'older people were not supposed to play with any degree of seriousness let alone train and try to improve' (Bill). This type of message provided strong signals about what and how 'someone my age' (Les) should behave. As David commented: 'It really annoys me when I'm working out at the gym and people look at me with a quizzical stare. I just think to myself, we're athletes, why shouldn't we train?' Most experienced some degree of embarrassment particularly during their initial experiences of reuniting with and playing sport. It was like 'being the odd one out as there are only a few of my age group involved in cycling and swimming' (Tim). What is more, having to re-learn the skills is a challenge, the body is on display (e.g. movement proficiency, body shape) and one's level of self-consciousness can easily be exaggerated, 
particularly if others are watching. What happens in this situation will influence whether or not one continues to participate. Edith recalled:

I was encouraged by others to just have-a-go but was very aware that I was on show and at first it is very difficult to feel comfortable. It had been a few years, quite a few, since I had been very active and there were concerns about my ability to 'keep up' and look reasonable. I think this is probably more difficult to cope with when you're older. I was lucky that my friends were very supportive and few others were around.

Although most participants had played team sports during their youth they were now all involved in individual activities (see Table I). Reasons for this included: the need to have control over personal time; freedom to practice and play as much or as little as possible; the level of competitiveness can be determined by the individual; and there was no need to rely on others for either training or having a game. Diane indicated 'It's important at my age not to have to depend too much on others. There's too many unpredictable things that can happen.' This view was endorsed by the others, particularly in relation to juggling time around family commitments and dealing with the ailments of self and others: 'In spite of what the mind says sometimes the body just doesn't want to play' (Ruth).

Irrespective of that reason for playing sport, having success was important. This occurred in a variety of ways and required some control over their body functioning (e.g. hand-eye co-ordination, balance, agility) as well as a degree of proficiency when performing the skills specific to the sport. Whilst all participants received plenty of support from young and old colleagues in the sporting environment, Mary contends one of the problems at first is:

Older people are encouraged to come along and have-a-go, but it's difficult to really enjoy it unless you stick to it for a while. It can also be frustrating particularly when you haven't played for a number of years. Your mind can remember what it used to be like but you just can't perform like you used to. It's not surprising that most people don't have much success at first. I can remember this well. It would have been very easy just to give up.

In spite of the frustrations all agreed that playing sport was not just a physical experience. There was a chance to socialise, meet new people and, most importantly, to do something that provided a great deal of personal satisfaction. As Ross explained:

When I play tennis it's not just running around the court that excites me. It's the friendship and chance to spend time with other men who have a similar interest. I enjoy the challenge of the games and always leave feeling good about myself, a kind of euphoria. My wife doesn't understand my excitement for 'hitting a ball' but I believe it definitely contributes to my quality of life. 


\section{Serious play}

By any definition, playing sport involves competition and each person responds to this in different ways depending on their previous experience, skill level and the context in which the game is being played. An appropriate level of competition and fairness was deemed important in order to value and enjoy one's involvement:

What can be more exciting than us 70-year-olds playing against others our own age? This is what I call a level playing field and is one reason why events like the Masters Games are so popular. You also get a chance to participate against people with whom they don't usually compete. (Bill)

There's a special atmosphere when you're involved in an event like the Masters Games with hundreds of other enthusiasts, quite a few of which are in my age group. It also provides the chance to meet new people and share stories with old friends. I find it's a real buzz to be involved, it's my Olympics. Of course there is also the chance to compete against new players in your age group of unknown ability. I find this exciting as there are only a few of us oldies that compete at the club meet. We aren't too serious at the club but in events like the Masters, it's serious stuff because some of the opponents are damned good. (Joan)

Irrespective of the nature of the game or event, winning always provided a special feeling. Whether this occurred by luck or by ability, seemed to be irrelevant but 'being the best on the day is always satisfying' (Richard). It would be pointless participating if there was 'no desire to perform in a way you felt pleased with and stretch your opponent: this makes for a good game' (Jill). However, this shouldn't be confused with a having-to-win attitude: 'just being able to perform in a way you knew you could was important' (Mary). All participants indicated that winning and losing was only a part of the sporting experience. Not surprisingly, they talked about the notion of competitiveness in broad terms and explained how success could be defined in a variety of ways:

I'm pretty competitive and irrespective of the event, I generally give it one hundred per cent. I'm the same with cryptic crosswords and just hate not to be able to finish them. There's a kind of satisfaction in knowing you can actually achieve something you really want to do. For me this is playing two games in a day. (Bill)

I like to play people who are better than me irrespective of their age. There are some great players to test yourself against and that makes it exciting. I mean, the outcome is important and I try to win but it doesn't really matter. That's probably why I still get nervous before participating in a big event like the Masters Games. (Jill) 
I go into a game thinking there's a chance to win, but the most important thing for me is to be consistent even though sometimes it seems as if I've never played the game before. I remember one event where I couldn't have played worse and felt pretty dejected afterwards. Although it's not too long before the laughter starts it's strange that I always remember these awful moments. (Mary)

In my sport you can play the men on equal terms and there is nothing more satisfying than beating a man. I'm not sure they really enjoy this! (Berl)

To be able to continue and compete in events like the Masters Games, all participants made adjustments to the way they performed some of the skills specific to their sport. This involved changing a part of their physical functioning (e.g. the arm action in swimming, leg kick in line dancing, back swing in golf) but not their attitude or desire to perform. They assumed, however, that others of their age would also experience a range of limitations and have to make similar adjustments. For Edith this meant:

Learning to rely as much on tactics and trying to out-think your opponent [as your] physical ability. Although you don't want to, you have to accept your limitations in spite of the frustration it causes because if you didn't you would give up. Of course, I assume that other competitors are experiencing similar problems. We tend to talk about our problems after the event. It's just a part of growing old and finding out how others cope.

Nevertheless, there was some concern expressed when discussing how they dealt with the declining level of functional capacity. Most raised the question of 'what if I get injured or become ill with one of those 'old people' diseases and can no longer compete or even participate?' (Ruth). In essence, such comments reflect a potential dilemma for all older people irrespective of whether or not they play sport. They believed, and in three cases prayed, that playing sport would help them to remain independent and maintain control over their health and wellbeing. Although currently enjoying what was described as a good quality of living, there was a feeling of uncertainty regarding the future and what 'tomorrow might bring' (Richard). Hence, most believed it was worthwhile 'playing sport until the end or, at least, that something unforeseen caused them to stop. After all, if I didn't play sport what else would I do? It's an important part of my life' (David).

Taking sport seriously satisfied a personal need but in some cases didn't occur without contention. Given their interest in the respective sports, most participants spent a considerable amount of time away from home. Hence, it was often necessary to negotiate with family members about, and sometimes juggle, their supposed duties and responsibilities. This dilemma wasn't confined only to those still living 
with their spouse. Sue, for example who had been widowed for seven years, was adamant she no longer fulfilled 'an assumed grandparent role by looking after the grand kids without warning. There are times when this has to fit around my schedule'. Ruth was just as resolute in suggesting when 'training for big events, there was no way I am going to make compromises to satisfy my children's needs unless there was an emergency. I remember once when my daughter called me a liberated oldie'. Although all participants took playing sport seriously, they were realistic about the place of sport in life. It was, as Joan said, 'just an activity' and there needed to the some sensitivity to balancing one's interest with the needs of others. However, this was more easily said than done; hence there was sometimes tension in the home. As Les explained:

I've had to venture into the garden on more than one occasion to retrieve my tennis racquet after my wife had thrown it there, as a way of expressing her opinion about my commitment. The issue is really about the amount of time I spend away from home, instead of doing other so-called 'important' things like gardening, cleaning, and caring for grandchildren. Thank God it's not an anti-sport campaign or I'd have to change my ways. But at the other extreme there are times when my family are really quite proud of me even though they think I'm getting past it. One day I may retire but at the moment, that's not a high priority. I'm having too much fun.

\section{Discussion}

Regularly participating in a diverse array of physical activities and playing sport was an important part of life for the participants in this study. Some could be described as being extremely active while others exercised on a more spasmodic basis. Irrespective of the type of activity or level of intensity, regular exercise had become a valued part of their existence. When talking about the 'things you get with ageing', they explained how their involvement was constrained by debilitating conditions. Nevertheless, these men and women located themselves in the discourse of good health and resisted the notion that ageing could be described solely as a biomedical problem highlighted by an encroaching decline in their physical ability. Their collective views echoed the extensive body of knowledge which endorses the belief that regular physical activity makes a significant contribution to one's state of wellbeing and quality of life in the later years (Feldman and Poole I 999, Huber I 997; Makosky r 996; Mathieu i 999; O'Brien and Horne I998; Rowe and Kahn I998; Shephard i997; Spirduso i995). Although these participants all experienced such benefits, there was some concern about the supposedly high proportion of the over-65- 
year-olds who remained relatively inactive. This was accentuated when considering that poor health is frequently cited as a reason to avoid being too physically active. To what extent this is a real concern is difficult to discern, as most older people deploy a variety of strategies to ensure they experience good health (self-defined) and consider ageing a positive experience (Atchley ı 999; Blaikie ı 999; Greenwald I997; Sugar and Morinelli I997). Partaking in regular physical activity may be desirable behaviour but, as Heikkinen (2000: 477) reported, each person has their own way of organising daily life in a way consistent with their abilities and state of wellbeing. This being the case, it is worth reflecting on the degree to which older people should be encouraged to modify their way of life.

In addition to concerns about health status, some participants believed that the assumed high levels of physical inactivity reinforced a stereotypical view of ageing. At a personal level, some comments implied what Erikson et al. ( I 986) called a tension between identity and despair in later life. Although not totally sympathetic, these participants expressed a sense of empathy regarding the physical and psychological challenge most older people had to confront when wanting to be more physically active. They also endorsed the contention that age alone could not fully explain or continually be used as an excuse for being physically inactive. It is possible the participants were in tune with the problematic of normalising ageing (Hepworth I 995), and sensitive about the 'mask of old age' (Conway and Hockey I 998). Whatever the reason, there is a need to challenge the traditional and static concept of an amorphous and undifferentiated old age (Featherstone and Hepworth (I995: 3I). Drawing on the beliefs expressed in this study, it can be argued that ageism and age discrimination provide a significant barrier for older people wanting to adopt a more physically active lifestyle. Acknowledging the complexity of such, Morgan (200I) encourages a rethink, or even rejection of conventional practices of exercise prescription, if the intention is to encourage a greater proportion of the older population to engage in a more physically active life.

Since taking up sport, all participants had to cope with what Minichiello et al. (2000) have termed 'negative interactions'. Many of these messages expressed a mix of social and cultural values as to how an older person should behave. Comments such as 'playing sport at your age' required careful negotiation and were considered discouraging, particularly during the initial phase of reactivating the physical self. In some cases the messages emanated from within families, whilst others were implied in the public campaigns and 
advertising intended to attract older people to 'join in'. Some messages were interpreted as focusing too much on exercise as a commodity, something that was purchased as a means to an end. Other images tended to ignore the notion of play and spontaneity, a fundamental characteristic if physical activity is to have a worthwhile meaning for self. As Kretchmar (200 I) noted, if the misinterpreted messages transfer to the exercise environment, the probability of continuation is considerably reduced.

At present there is some confusion about how best to market physical activity if a behaviour change is the desired outcome (Dishman 200I). Whilst a small percentage of older people will respond accordingly and become more physically active, Grant and Stothart (1999) argue that there will never be a revolution where masses of those in their later years become 'exercise junkies'. This is not to suggest we should abandon the search for a more comprehensive understanding of this phenomenon or adopt alternative strategies that invite older people to make a transition to a more physically active lifestyle. Whatever occurs will need to take cognizance of the ongoing process of construction and reconstruction of ageing within our respective communities (Featherstone and Hepworth i $995: 46)$.

Later life may be replete with opportunities for continual growth and development, but it should be remembered that those born 70 or more years ago have lived through a time when this was not always the case. Life expectancy was also much shorter. What is more, many remember when rest was advocated as a necessity in later life (Kirk I997) and women were expected to become secluded and withdrawn as they aged (Vertinsky i 995). There was also a time when ageing was more akin to a slow, downward, inward spiral until eventually sliding into oblivion (Bortz I99I). Moreover, some developmental theorists have postulated that older adults were 'grown up' and could develop no further (Coakley i 998). Not surprisingly, those now in their 7os remember their parents' generation being discouraged from engaging in any activity that might put unnecessary demands on the body. Although the message is now quite different, many older people still overestimate the perceived dangers of being physically active whilst underestimating their physical capabilities. Such confusion is partially attributable to the many contradictory messages to which older people have been exposed across their life time.

Incorporating moderate levels of physical activity into one's routine need not require much time or effort. However, having more discretionary time, something commonly associated with later life, is insufficient by itself to promote this type of behaviour change (Mathieu 
I 999). Neither does knowing about the potential benefits that might be gained by being physically active, entice change (Chodzko-Zajko 2000; Dishman 200I; O'Brien Cousins and Horne i999). The participants in this study agreed that to be of any consequence, freelychosen physical activity must be personally meaningful and valued by the self. Hence, when trying to unravel any aspect of this aspect of life there is a need to recognise older individuals as a multiple, situational self (Blaikie I999). This is something we need to learn more about (Kretchmar 200I): as previously noted, ageing alone is considered a weak indicator of both participation in, and disengagement from, physical activity (Atchley i 999).

Like many older people, these ageing athletes had to deal with some type of irrevocable change in their functional capacity and subsequent loss of ability. At times their ailments were frustrating and inconvenient but, on most occasions, these were considered more of a nuisance factor than an excuse to disengage, something common with the majority of older adults (Dunlap and Barry ı 999; Satariano et al. 2000; O'Brien Cousins 2000). Consequently, the participants approached their respective activities, particularly preparation for and playing sport, with caution. They controlled their levels of activity to ensure a congruence between their state of health and sport aspirations, which is often a difficulty in the beginning stages. Acceptance of their disposition reflected the views of Atchley ( I999) who claimed that negative changes, in this case in body function, may influence behaviour and feelings, but not necessarily have negative consequences (i.e. withdrawing from or injuries while playing sport). It can be argued that having the desire, and knowing how to manage the ailing body, helped provide a sense of self-worth, identity and empowerment. According to Roberts (I999), these traits are consistent with older people committed to a freely-chosen leisure activity irrespective of its type or form.

By focusing on the beliefs of older people, this study illustrates how the role and meaning of physical activity in later life is expansive, dynamic and completely imbued with multiple interpretations. Rather than be concerned with the correctness of their factual references, the narrative data gave significance to events drawn from the experiences and the relationships attributed to a physically active life (Kerry and Armour 2000; Kluge 200 I; Polkinghorne I 996; Poole 200 I). Although the gerontology literature tends to ignore older peoples' perceptions and beliefs (Blaikie ı 999; Carlsen i 996; Conway and Hockey r 998; Ruth and Kenyon I996), such information can make a notable contribution to the creation of a culture of positive ageing and old age 
(Featherstone and Hepworth i 995). Furthermore, by giving credence to the voice of older people, different truths from those to which we are accustomed about ageing and physical activity, emerge (Markula et al. $200 \mathrm{I})$. The stories these older people told about their experiences, and the beliefs they held about ageing and physical activity, help illustrate the resilience of the ageing body. They also illustrate how ageing is constantly being negotiated at an individual and societal level, and how successful ageing occurs in different ways.

\section{References}

Abel, E. and Sankar, A. I995. Introduction: the uses and evaluation of qualitative research. Research on Aging, 17, I, 3-7.

Atchley, R. 1999. Continuity and Adaptation in Aging: Creating Positive Experiences. The John Hopkins University Press, Baltimore.

Blaikie, A. I 999. Ageing and Popular Culture. Cambridge University Press, Cambridge.

Blair, S. and Wei, M. 200o. Sedentary habits, health, and function in older men and women. American Fournal of Health Promotion, 15, 2, 84-93.

Bortz, W. r 99 I. We Live too Short and Die too Long: how to Achieve and Enjoy your Natural I0o-Year-Plus Life Span. Bantam Books, New York.

Carlsen, M. 1996. Creative Aging : a Meaning Making Perspective. W. W. Norton Co, New York.

Chodzko-Zajko, W. 200o. Successful ageing in the new millennium: the role of regular physical activity. Quest, 52, 333-43.

Coakley, J. 1998. Sport in Society: Issues and Controversies (6th Edition). Mosby-Year Book, St Louis.

Conway, S. and Hockey, J. i 998. Resisting the 'mask' of old age? The social meaning of lay health beliefs in later life. Ageing and Society, 18, 469-94.

Denison, J. and Reinhart, R. 2000. Introduction: imaging sociological narratives. Sociology of Sport Fournal, I7, I-4.

Denzin, N. I 997. Interpretive Ethnography: Ethnographic Practices for the 2Ist Century. Sage, California.

Dishman, R. 200 I. The problem with exercise adherence: fighting sloth in nations with market economies. Quest, 53, 3, 279-94.

Dunlap, J. and Barry, H. I 999. Overcoming exercise barriers in older adults. The Physician and Sport Medicine, 27, I I, 69-75.

Erikson, E., Erikson, J. and Kivnick, H. ig86. Vital Involvement in Old Age. W. W. Norton, London.

Featherstone, M. and Hepworth, M. I 995. Images of positive ageing: a case study of retirement choice magazine. In Featherstone, M. and Wernick, A. (eds), Images of Aging; Cultural Representation in Later Life. Routledge, London, 29-47.

Featherstone, M. and Wernick, A. I995. Images of Ageing; Cultural Representation in Later Life. Routledge, London.

Feldman, S. and Poole, M. i 999. Positioning older women. In Poole, M. and Feldman, S. (eds), A Certain Age: Women Growing Older. Allen and Unwin, Sydney, 3-1 7 .

Grant, B. and Stothart, B. I 999. Aging, leisure and active living. The Australian Council for Health Physical Education and Recreation. Healthy Lifestyles fournal, 46, 2, 29-32.

Grant, B. and O'Brien Cousins, S. 200 I. Ageing and physical activity: The promise of qualitative research. Fournal of Aging and Physical Activity, 9, 3, 237-44. 
Greenwald, J. r997. Age is no barrier. Time Magazine, 22 September.

Hardcastle, S. and Taylor, A. 200 I. Looking for more than weight loss and fitness gain: psychological dimensions among older women in a primary-care exercise referral program. Fournal of Aging and Physical Activity, 9, 3 1 3-28.

Heikkenen, R. 2000. Ageing in an autobiographical context. Ageing and Society, 2o, $467-83$.

Henderson, K., Ainsworth, B., Stolarzcyk, L., Hootman, J. and Levin, S. I 999. Notes on linking qualitative and quantitative data: the cross cultural physical activity participation study. Leisure Sciences, 21, 247-55.

Hepworth, M. I995. Positive ageing: what is the message? In Bunton, R, Nettleton, S. and Burrows, R. (eds), The Sociology of Health Promotion: Critical Analyses of Consumption Lifestyle and Risk. Routledge, London, i 76-90.

Hepworth, M. 200o. Stories of Ageing. Open University Press, Buckingham.

Huber, G. I 997. Introduction. In Huber, G. (ed), Healthy Aging. Proceedings of $4^{\text {th }}$ International Congress, Physical Activity, Ageing and Sports. Health Promotion Publications, Heidelberg, I 7-24.

Jamieson, A. Harper, S. and Victor, C. (eds) 1997. Critical Approaches to Ageing and Later Life. Open University Press: Buckingham.

Kelly, J. I 993. Varieties of activity. In Kelly, J. (ed), Activity and Aging: Staying Involved in Later Life. Sage, California, I65-79.

Kenyon, G. and Randall, W. 1997. Restorying our Lives: Personal Growth through Autobiographical Reflection. Praeger, Westport.

Kerry, D. and Armour, K. 2000. Sport sciences and the promise of phenomenology: Philosophy, method and insight. Quest, 52, I-I 7 .

Kilgman, E., Hewitt, M. and Crowell, E. I 999. Recommending exercise to healthy older adults. The Physician and Sport Medicine, 27, I I, 42-62.

Kirk, H. r997. Facing the historical 'rest-in-old-age' paradigm. In Huber, G. (ed),

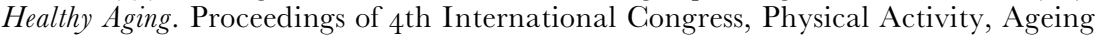
and Sports. Health Promotion Publications, Heidelberg, 63-5.

Kluge, M. 200I. Understanding the essence of a physically active lifestyle: a phenomenological study of women 65 and older. Fournal of Aging and Physical Activity, 9, 4, 438-6r.

Kretchmar, S. 200 I. Duty, habit and meaning: different faces of adherence. Quest, 53, 3 I $8-25$.

Kuhn, T. 1970. The Structure of Scientific Revolutions. University of Chicago Press, Chicago.

Langley, D. and Knight, S. i 999 . Continuity in sport participation as an adaptive strategy in the ageing process: a lifespan narrative. Fournal of Aging and Physical Activity, 7, 32-54.

McPherson, B. I994. Sociocultural perspective's on ageing and physical activity. Journal of Aging and Physical Activity, 2, 329-53.

Makosky, L. I996. The active living concept. In Quinney, A., Gauvin, L. and Wall, T. (eds), Proceedings of the International Conference on Physical Activity, Fitness and Health. Human Kinetics, Champaign, 246-54.

Markula, P., Grant, B. and Denison, J. 200ı. Qualitative research and ageing and physical activity: multiple ways of knowing. Fournal of Aging and Physical Activity, 9, $3,245^{-64}$.

Mathieu, M. i 999. The Surgeon General's report and leisure services for older adults. Journal of Physical Education, Recreation and Dance, 7o, 3, 28-3I.

Minichiello, V., Browne, J. and Kendig, H. 2000. Perceptions and consequences of ageism: views of older people. Ageing and Society, 20, 253-78.

Morgan, W. 200 I. Prescription of physical activity: a paradigm shift. Quest, 53, 3, 366-82. 
O'Brien Cousins, S. 200o. My heart couldn't take it: older women's belief about exercise and risks. Journal of Gerontology: Psychological Sciences, 55, 283-94.

O'Brien Cousins, S. and Horne, T. I 999. Active Living Among Older Adults: Health Benefits and Outcomes. Taylor and Francis, Philadelphia.

O'Brien Cousins, S. and Janzen, W. I998. Older adults beliefs about exercise. In O'Brien Cousins, S. (ed), Exercise, Ageing and Health: Overcoming Barriers to an Active Old Age. Taylor and Francis, Philadelphia, 7 $\mathrm{I}^{-96}$.

Poole, M. 200 I. Fit for life: older women's commitment to exercise. Fournal of Aging and Physical Activity, 9, 300-I2.

Poole, M. and Feldman, S. (eds). I 999. A Certain Age: Women Growing Older. Allen and Unwin, Sydney.

Roberts, K. I999. Leisure in Contemporary Society. CABI Publishing, Oxon.

Rowe, J. and Kahn, R. i998. Successful Aging. Pantheon Books, New York.

Ruchlin, H. and Lachs, M. I999. Prevalence and correlates of exercise among older adults. Fournal of Applied Gerontology, I8, 34 I-57.

Ruth, J. and Kenyon, G. I996. Biography in adult development and aging. In Birren, J., Kenyon, G., Ruth, J., Schroots, J. and Svensson, T. (eds), Ageing and Biography: Exploration in Adult Development. Springer Pub, New York, I-20.

Sankar, A. and Gubrium, J. I 994. Introduction. In Gubrium, J. and Sankar, A. (eds), Qualitative Methods in Ageing Research. Sage, California, i-vi.

Satariano, W., Haight, T. and Tager, I. 200o. Reasons given by older people for limitation of leisure time physical activity. Fournal of the American Geriatrics Society, $\mathbf{4 8}$, $5^{\mathrm{O}} 5^{-\mathrm{I}} 2$.

Shepherd, R. 1997. Aging, Physical Activity and Health. Human Kinetics, Champaign.

Slater, R. 1995. The Psychology of Growing Old: Looking Forward. Open University Press, Buckingham.

Sparkes, A. i992. The paradigm debate: an extended review and a celebration of difference. In Sparkes, A. (ed), Research in Physical Education and Sport: Exploring Alternative Visions. The Falmer Press, London, 9-6o.

Spirduso, W. i 995. Physical Dimensions of Aging. Human Kinetics, Champaign.

Sugar, J. and Morinelli, R. I 997. Healthful aging: a social perspective. Fournal of Activities, Adaptation and Aging, 24, I, I-I 2.

Tinning, R. I997. Performance and participation discourses in human movement: toward a socially critical physical education. In Fernandez-Balboa, J. (ed), Critical Postmodernism in Human Movement, Physical Education and Sport. State University of New York Press, Albany, 99-120.

van Manen, M. i998. Researching Lived Experience: Human Science for an Action Sensitive Pedagogy (2nd Edition). The Althouse Press, Ontario.

Vertinsky, P. I 995. Stereotypes of ageing women and exercise: a historical perspective. Fournal of Ageing and Physical Activity, 3, 223-37.

Willing, J. I $98 \mathrm{I}$. The Reality of Retirement the Inner Experience of Becoming a Retired Person. William Morrow, New York.

Wolinsky, F., Stump, T. and Clark, D. r 995. Antecedents and consequences of physical activity and exercise among older adults. The Gerontologist, 35, 45 I-62.

World Health Organisation. I 997. Joint United Nations World Health Organisation Conference on Healthy Aging. Bulletin on Aging, $\mathbf{I}, 5$.

Accepted 4 September 200I

Address for correspondence:

Department of Sport and Leisure Studies, University of Waikato, Bag 3i05, Hamilton, New Zealand.

e-mail: bcg@waikato.ac.nz 